\title{
Hyalinizing clear cell carcinoma of the bronchial glands: presentation of three cases and pathological comparisons with salivary gland counterparts and bronchial mucoepidermoid carcinomas
}

\author{
Manabu Takamatsu $^{1} \cdot$ Yukiko Sato $^{1} \cdot$ Mariko Muto $^{1} \cdot$ Hiroko Nagano $^{1} \cdot$ Hironori Ninomiya $^{1} \cdot$ Rie Sakakibara $^{1}$. \\ Satoko $\mathrm{Baba}^{2} \cdot$ Seiji Sakata ${ }^{2} \cdot$ Kengo Takeuchi $^{1,2} \cdot$ Sakae Okumura $^{3} \cdot$ Yuichi Ishikawa $^{1}$
}

Received: 17 October 2017 / Revised: 12 December 2017 / Accepted: 17 December 2017 / Published online: 12 February 2018

(c) United States \& Canadian Academy of Pathology 2018

\begin{abstract}
Hyalinizing clear cell carcinoma of the bronchial glands is a very rare tumor. Since only five reports describing six tumors have been published to date, only a little is known about specific histologic findings and clinical features. Because of its rarity, hyalinizing clear cell carcinoma has not been described in the latest WHO classification of pulmonary tumors yet. Here we present three cases of bronchial hyalinizing clear cell carcinomas, confirmed by both fluorescence in situ hybridization (FISH) and RT-PCR, focusing on histologic and immunohistochemical characteristics in a comparison with three cases of salivary gland origin. In addition, we compared immunohistochemical features with bronchial mucoepidermoid carcinoma, a lesion that needs to be taken into account in differential diagnosis of hyalinizing clear cell carcinoma. All our bronchial hyalinizing clear cell carcinoma cases were surgically resected. Histologically, tumor cells showed clear to eosinophilic cytoplasm with hyalinizing stroma in various proportions, resembling those of salivary gland origin. Immunohistochemically, tumor cells were positive for CK7, CK5/6, p40, p63, and ATF1, while they were negative for TTF1, Napsin A, HMB45, and SOX10. The CK5/6 staining pattern varied in mucoepidermoid carcinomas, while that of hyalinizing clear cell carcinoma was uniformly positive. FISH revealed EWSRI-ATF1 fusion, and RT-PCR with sequencing confirmed specificity of the chimeric gene for hyalinizing clear cell carcinoma. Clinically, bronchial hyalinizing clear cell carcinoma was characterized by occurrence in the fourth to sixth decades, no link with smoking history, and a predilection for the right lung, in line with previous reports. In summary, our study confirmed that the bronchial hyalinizing clear cell carcinoma is a histologically and genetically identical tumor to that of salivary gland origin, and that gene rearrangement analysis can play a critical role in distinction from mucoepidermoid carcinoma.
\end{abstract}

Electronic supplementary material The online version of this article (https://doi.org/10.1038/s41379-018-0025-7) contains supplementary material, which is available to authorized users.

$\triangle$ Yuichi Ishikawa

ishikawa@jfcr.or.jp

1 Division of Pathology, The Cancer Institute; Department of Pathology, The Cancer Institute Hospital, Japanese Foundation for Cancer Research, Tokyo 135-8550, Japan

2 Pathology Project for Molecular Targets, The Cancer Institute, Japanese Foundation for Cancer Research, Tokyo 135-8550, Japan

3 Department of Thoracic Surgery, The Cancer Institute Hospital, Japanese Foundation for Cancer Research, Tokyo 135-8550, Japan

\section{Introduction}

Salivary gland-type neoplasms of the bronchus constitute a rare primary lung tumor entity [1]. There are several types of tumors known to arise in the bronchus: mucoepidermoid carcinoma, adenoid cystic carcinoma, epithelialmyoepithelial carcinoma, and pleomorphic adenoma [25]. All of these four tumors are described in the WHO classification [6]. Some of these tumors are also common in salivary glands, so that their sites of origin in the bronchus have been supposed to be the bronchial submucosal glands [7]. Hyalinizing clear cell carcinoma of the salivary gland is a rare tumor, first reported in 1994 [8]. It most commonly arises in the head and neck region, including the parotid gland, nasal cavity, and pharynx [9-12]. Hyalinizing clear 
cell carcinoma of the bronchial gland is extremely rare, with only five reports published hitherto [13-17]. In our hospital, only three bronchial hyalinizing clear cell carcinoma cases were found in all pulmonary malignancies from 2001 to 2016. For this reason, little is known about its specific histologic appearance and similarities to salivary gland counterparts. In addition, since the salivary hyalinizing clear cell carcinoma can metastasize to regional lymph nodes or distant sites [18, 19], it is necessary to elucidate clinical characteristics of bronchial hyalinizing clear cell carcinoma and its metastatic potential.

Several researchers have been reported EWSRI gene rearrangement detected by fluorescence in situ hybridization (FISH) in both salivary and bronchial hyalinizing clear cell carcinomas [13-16, 20]. Antonescu et al. [20] further demonstrated two cases of salivary hyalinizing clear cell carcinoma harboring EWSR 1-ATF1 chimeric genes detected by reverse transcription-polymerase chain reaction (RTPCR). Only two cases of bronchial hyalinizing clear cell carcinoma harboring such a fusion gene has been reported $[14,17]$. Because of its rarity and histologic similarity, it is difficult to distinguish hyalinizing clear cell carcinoma from other salivary gland-type tumors, such as mucoepidermoid carcinoma. Therefore, detection of a specific chimeric gene is critical for correct diagnosis. In addition, RT-PCR generally requires fresh samples to extract nucleic acid in order to confirm the presence of a fusion gene, so that a more convenient method such as a fusion assay for FISH is needed.

In this study, we present three bronchial hyalinizing clear cell carcinoma cases, focusing on their histologic features compared with hyalinizing clear cell carcinomas of salivary gland origin. In addition, we compared immunohistochemical features with bronchial mucoepidermoid carcinoma, a lesion requiring differential diagnosis from hyalinizing clear cell carcinoma. We also performed fusion FISH analysis using probes both EWSRl and ATFl on formalin-fixed paraffin-embedded sections, and additionally confirmed the fusion for all three cases with RT-PCR and Sanger sequencing.

\section{Materials and Methods}

\section{Patients}

\section{Bronchial cases}

Case B1: a 52-year-old Japanese woman underwent right middle-lower lobectomy for a solid mass located in the segmental bronchus.

Case B2: a 35-year-old Japanese woman, who had a smoking habit, complained of persistent coughing with fever. Chest X-rays revealed complete atelectasis of the right lower lung, and a mass protruding into the lumen of intermedius bronchus was observed on bronchoscopy. Right middle-lower lobectomy with regional lymph node dissection was performed.

Case B3: In a 56-year-old Japanese woman, an abnormal shadow was pointed out on the chest X-ray, and she underwent right middle-lower lobectomy with regional lymph node dissection for a solid mass located in the secondary bronchus. An abnormal appearance on chest computed tomography had been pointed out 7 years before surgery.

None of the patients had any history of salivary gland tumors, and all are currently alive without local recurrence or metastasis. The frequency of this tumor is $0.09 \%$ (3/ 3337) among primary lung tumors resected during 2000-2016 in the Cancer Institute Hospital, Tokyo $(n=$ 3337). Further details of these cases are listed in Table 1a.

\section{Salivary gland cases}

Case S1: a 44-year-old Japanese woman, who had a smoking habit, underwent subtotal tongue root resection for a solid mass located in the anterior mesopharynx after chemoradiation therapy.

Case S2: an 80-year-old Japanese woman underwent total glosso-laryngectomy for a solid mass located in the anterior mesopharynx. Twelve months after resection, multiple lung metastases were identified.

Case S3: a 64-year-old Japanese man, who had a smoking habit, underwent buccal resection for a solid mass located in the buccal mucosa.

The patients of cases S1 and S3 are alive without local recurrence or metastasis. A summary of details is given in Table $1 \mathrm{~b}$.

In addition, we examined seven bronchial mucoepidermoid carcinoma cases diagnosed and treated in our hospital, for comparison of histologic and immunohistochemial features.

\section{Sample preparation and histologic assessment}

Serial 5-mm-thick tissue slices were cut from resected specimens fixed with $20 \%$ buffered formalin, embedded in paraffin, and 4- $\mu$ m-thick sections were stained with hematoxylin and eosin. In case $\mathrm{S} 1$, the specimens were decalcified before paraffin embedding. All cases were initially diagnosed by two pathologists, and reviewed by another pathologist, a specialist in oral pathology. Each whole section of bronchial and salivary hyalinizing clear cell carcinoma cases was assessed for proportions of characteristic components graded into - (none), -l+ (spot), + (focal), ++ (substantial), and +++ (prominent). Histologic 


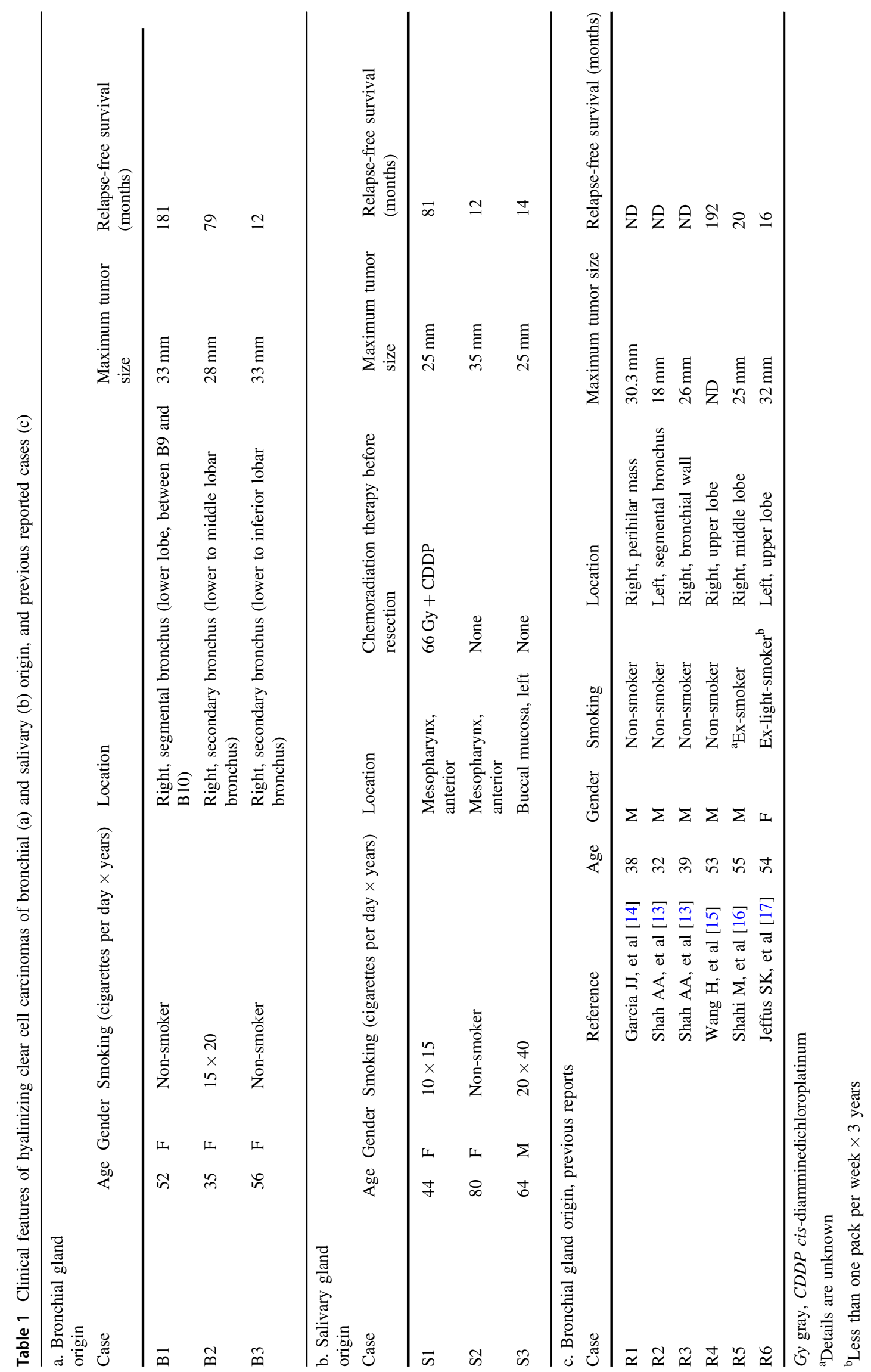


scoring for bronchial hyalinizing clear cell carcinoma and mucoepidermoid carcinoma was accomplished based on the salivary mucoepidermoid carcinoma grading system [21].

\section{Immunohistochemistry}

Immunostaining was performed for all bronchial and salivary hyalinizing clear cell carcinoma cases. Paraffinembedded $4-\mu \mathrm{m}$-thick sections were stained with following antigens: CK7, CK5/6, Np63 (p40), p63, TTF1, Napsin A, S-100, HMB45, Melan A, SOX10, ATF1, and Ki-67. Primary antibodies used are listed in Supplementary table. All staining was performed using an auto-stainer, Leica Bond-III (Leica Biosystems, Melbourne Pty Ltd., Australia). Only nuclear staining was considered positive for p40, p63, TTF1, SOX10, ATF1, and Ki-67.

Bronchial mucoepidermoid carcinomas were stained for CK7, CK5/6, p40, p63, TTF1, Napsin A, SOX10, and ATF1. We compared hyalinizing clear cell carcinoma and mucoepidermoid carcinoma by the five-graded scoring system depending on approximate proportions of positive cells according to the previous report [22], with definitions as follows: score $0(0 \%)$, score $1(1-25 \%)$, score 2 (26-50\%), score $3(51-75 \%)$, and score 4 (76-100\%). Average scores of hyalinizing clear cell carcinoma and mucoepidermoid carcinoma were calculated, and compared by the unpaired Student's $t$ test. The diagnosis of mucoepidermoid carcinoma was confirmed by MAML2 gene rearrangement analysis using RT-PCR or FISH (data not shown).

\section{FISH analysis}

FISH assays for EWSRI-ATF1 gene fusion were performed on formalin-fixed paraffin-embedded sections in all three bronchial hyalinizing clear cell carcinoma cases. Unstained sections (4- $\mu \mathrm{m}$-thick) were subjected to hybridization with the EWSRI break-apart probe kit (Vysis LSI EWSRI dualcolor, break-apart rearrangement probe; Abbott Molecular) with bacterial artificial chromosome clone-derived probes for ATF1 (CTD-2174I21). We performed the EWSR1 split assay using the same probes also for all three salivary hyalinizing clear cell carcinoma cases.

\section{RT-PCR and Sanger sequencing}

Fresh frozen samples from each tumor were used to extract total RNA. In addition, normal lung tissue of case B2 was used as a control. According to previous reports, we used a primer set to detect a EWSR1-ATF1 fusion gene harboring a specific break point in the hyalinizing clear cell carcinoma as follows: 5'-TCTAGGCCCACCTGTAGATCC (forward) and $5^{\prime}$-GTGAGGAGCCTATGCTGTCG (reverse), the
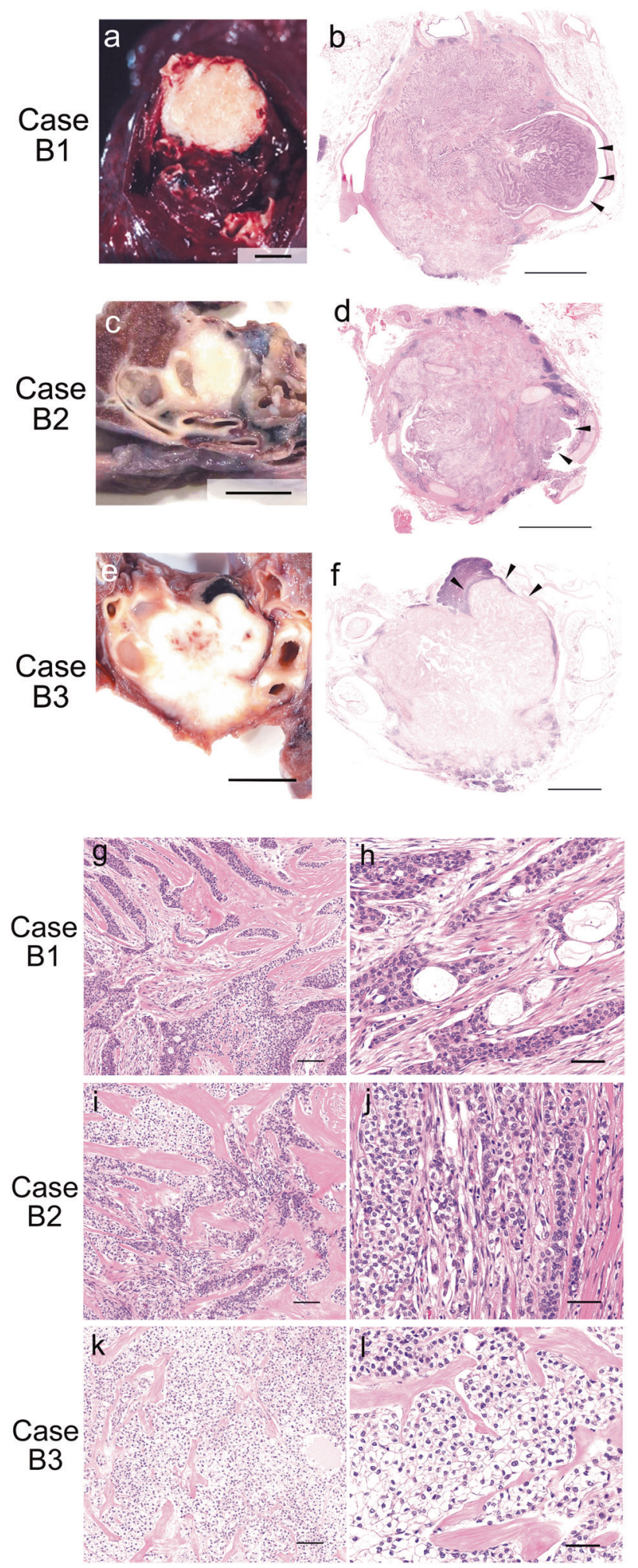

Fig. 1 Gross and histologic findings of bronchial hyalinizing clear cell carcinomas. The cut surfaces show well-demarcated lesions, creamy whitish (a, c), or whitish (e) in color. Tumor protrusion into the bronchi (b, d, arrow heads) is evident, with invasion of a peribronchial lymph node (f, arrow heads). Note the trabecular pattern (g), nest formation (k), and mixed features (i), with prominent hyalinized collagen. Predominant eosinophilic cells (h), clear cells (l), and their mixture (j) are evident in various proportions. (Hematoxylin and eosin staining. Scale bars are $10 \mathrm{~mm}$ in (a, c), and (e), 5 $\mathrm{mm}$ in $(\mathbf{b}, \mathbf{d})$, and $(\mathbf{f}), 100 \mu \mathrm{m}$ in $(\mathbf{g}, \mathbf{i})$, and $(\mathbf{k})$, and $50 \mu \mathrm{m}$ in $(\mathbf{h}, \mathbf{j}$, and $\mathbf{l})$.) 
Table 2 Histologic comparison of the bronchial and salivary hyalinizing clear cell carcinomas

\begin{tabular}{|c|c|c|c|c|c|c|c|c|c|c|}
\hline Case & $\begin{array}{l}\text { Clear } \\
\text { cytoplasm }\end{array}$ & $\begin{array}{l}\text { Eosinophilic } \\
\text { cytoplasm }\end{array}$ & $\begin{array}{l}\text { Mucin } \\
\text { production }\end{array}$ & $\begin{array}{l}\text { Mucin- } \\
\text { rich } \\
\text { cells }\end{array}$ & $\begin{array}{l}\text { Glandular } \\
\text { formation }\end{array}$ & $\begin{array}{l}\text { Trabecular } \\
\text { structure }\end{array}$ & $\begin{array}{l}\text { Nest } \\
\text { structure }\end{array}$ & Keratinization & $\begin{array}{l}\text { Hyalinizing } \\
\text { stroma }\end{array}$ & $\begin{array}{l}\text { Lymphoid } \\
\text { cuff } \\
\text { formation }\end{array}$ \\
\hline B1 & + & +++ & + & - & + & +++ & + & - & ++ & + \\
\hline B2 & ++ & ++ & + & - & + & ++ & ++ & - & +++ & + \\
\hline B3 & +++ & + & $+1-$ & - & $+/-$ & + & +++ & - & ++ & + \\
\hline $\mathrm{S} 1$ & + & +++ & $+1-$ & - & $+/-$ & ++ & ++ & - & + & $+1-$ \\
\hline $\mathrm{S} 2$ & +++ & + & $+1-$ & - & $+1-$ & + & +++ & - & ++ & $+1-$ \\
\hline S3 & +++ & + & $+1-$ & - & $+1-$ & + & +++ & - & ++ & + \\
\hline
\end{tabular}

Fig. 2 Histologic appearance of bronchial mucoepidermoid carcinomas. a A clear cell component (right) and an eosinophilic intermediate cell component (left) are gradually transitioning into each other. b Prominent mucin-rich cells (right) and intermediate cells (left). c A clear cell component with hyalinized collagen bundles (bottom). d Clear to eosinophilic components with occasional gland formation (arrow heads). (Hematoxylin and eosin staining. Scale bars are $50 \mu \mathrm{m}$.)

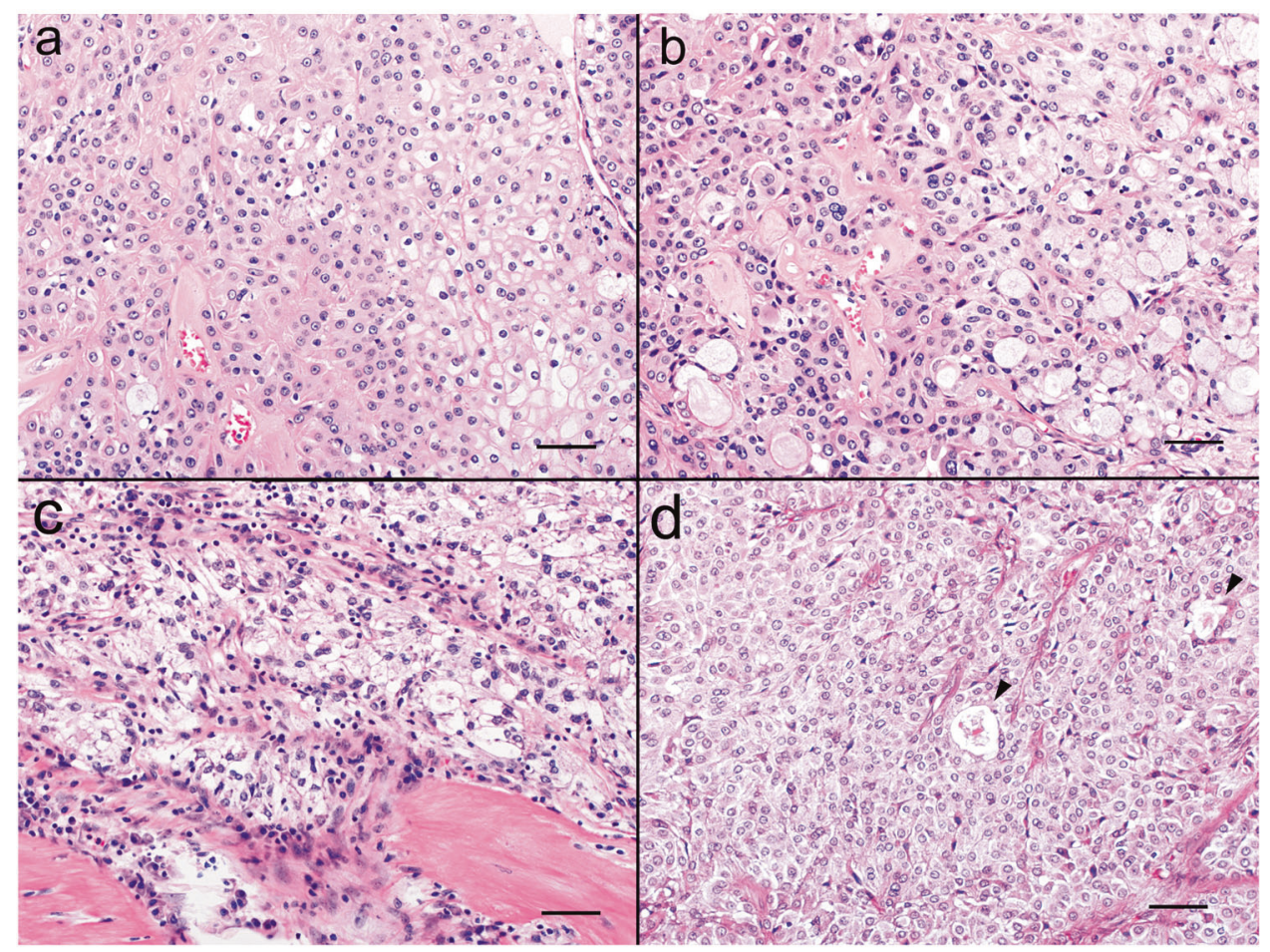

product size of which was $185 \mathrm{bp}[14,20]$. To check the sample RNA quality, a housekeeping gene ACTB was amplified using 5'-AGAAAATCTGGCACCACACC (forward) and 5'-AGAGGCGTACAGGGATAGCA (reverse) as primers. We performed Sanger sequencing to confirm the specificity of amplified products.

\section{Results}

\section{Gross and microscopic findings}

Grossly, the tumors were located adjacent to the bronchi or protruded into the bronchial lumen, with whitish cut surfaces and relatively well-demarcated borders (Fig. 1a, c, e). In case B3, the tumor directly invaded a peribronchial lymph node (Fig. 1e). Mucous impaction was observed in bronchi distal from the tumors in cases B2 and B3, possibly due to obstruction (Fig. 1c, e).

Tumor cells had round to oval nuclei with inconspicuous nucleoli, and demonstrated clear to eosinophilic cytoplasm (Fig. 1h, j, 1). The nuclear-cytoplasmic ratio was lower in clear than in eosinophilic cells (Fig. 1h, j, l). The proportions of cells with clear or eosinophilic cytoplasm differed among the cases (Table 2), and gradual transition was evident (Fig. 1i). Tumor cells grew with a prominent trabecular pattern in case B1 (Fig. 1g), whereas case B3 showed predominant nest formation (Fig. 1k). Occasional gland formation was identified in all cases, this being most frequent in case B1 (Fig. 1h). Although focal mucin production was identified in most of the cases, no mucin-rich cells were observed, which in contrast were almost always seen 
in mucoepidermoid carcinoma (Fig. 2a, b, d). Characteristic hyalinized acellular collagen bundles were easily recognized within all hyalinizing clear cell carcinomas (Fig. 1g, i, k), and also within mucoepidermoid carcinomas (Fig. 2c). Similarly, salivary hyalinizing clear cell carcinoma showed various histologic appearances, but with the same characteristic features as their bronchial counterparts (Fig. 3, Table 2). Mucin production and glandular formation were slightly less frequent in salivary hyalinizing clear cell carcinoma (Table 2). In case S1, the patient underwent chemoradiation therapy before resection, but there was no obvious granuloma or scar formation (Fig. 3b, g, h). Both bronchial and salivary hyalinizing clear cell carcinoma lacked keratinization (Figs. 1 and 3). Histologic details are summarized in Table 2.

Histologic scoring revealed one of the hyalinizing clear cell carcinoma cases to be an intermediate-grade tumor, while the other hyalinizing clear cell carcinoma and mucoepidermoid carcinoma cases were low grade (Table 3a). Neural invasion was more frequent in hyalinizing clear cell carcinoma than with mucoepidermoid carcinoma (Table 3a).

\section{Immunohistochemical findings}

Tumor cells were positive for CK7, CK 5/6, p40, and p63, indicating characteristics of basal cells or squamous cells (Fig. 4a, b, d, e). In contrast, TTF1, Napsin A, HMB45, and Melan A were uniformly negative in all cases. Tumor cells were negative for S-100. However, some intermingled cells were positive for S-100 (Fig. 4c) as well as for CD1a (Fig. 4f), implying a Langerhans cell nature. Ki-67 labeling was ranged from 3 to $10 \%$, indicating low proliferative activity (Fig. 4i). Whereas the tumor cells were positive for ATF1, non-tumor cells including lymphocytes, acinar cells of bronchial glands, and ciliated bronchial epithelia were also positive (Fig. 4g). Immunohistochemical scoring for hyalinizing clear cell carcinoma and mucoepidermoid carcinoma revealed that CK5/6 positivity was significantly higher in the hyalinizing clear cell carcinoma than in the mucoepidermoid carcinoma (Table 3b). SOX10, a marker of acinar differentiation of bronchial glands, was consistently negative in both hyalinizing clear cell carcinoma and mucoepidermoid carcinoma (Table $3 \mathrm{~b}$ ), suggesting that these tumors are not of acinar cell origin. There were no differences in ATF1 positivity between hyalinizing clear cell carcinoma and mucoepidermoid carcinoma (Table $3 b$ ).

\section{FISH analyses}

In all bronchial hyalinizing clear cell carcinoma cases, $5^{\prime}$ EWSR1 (red signals) and 3'-EWSRl (green signals) showed split signals in $>50 \%$ of cells (Fig. 5a, left column).

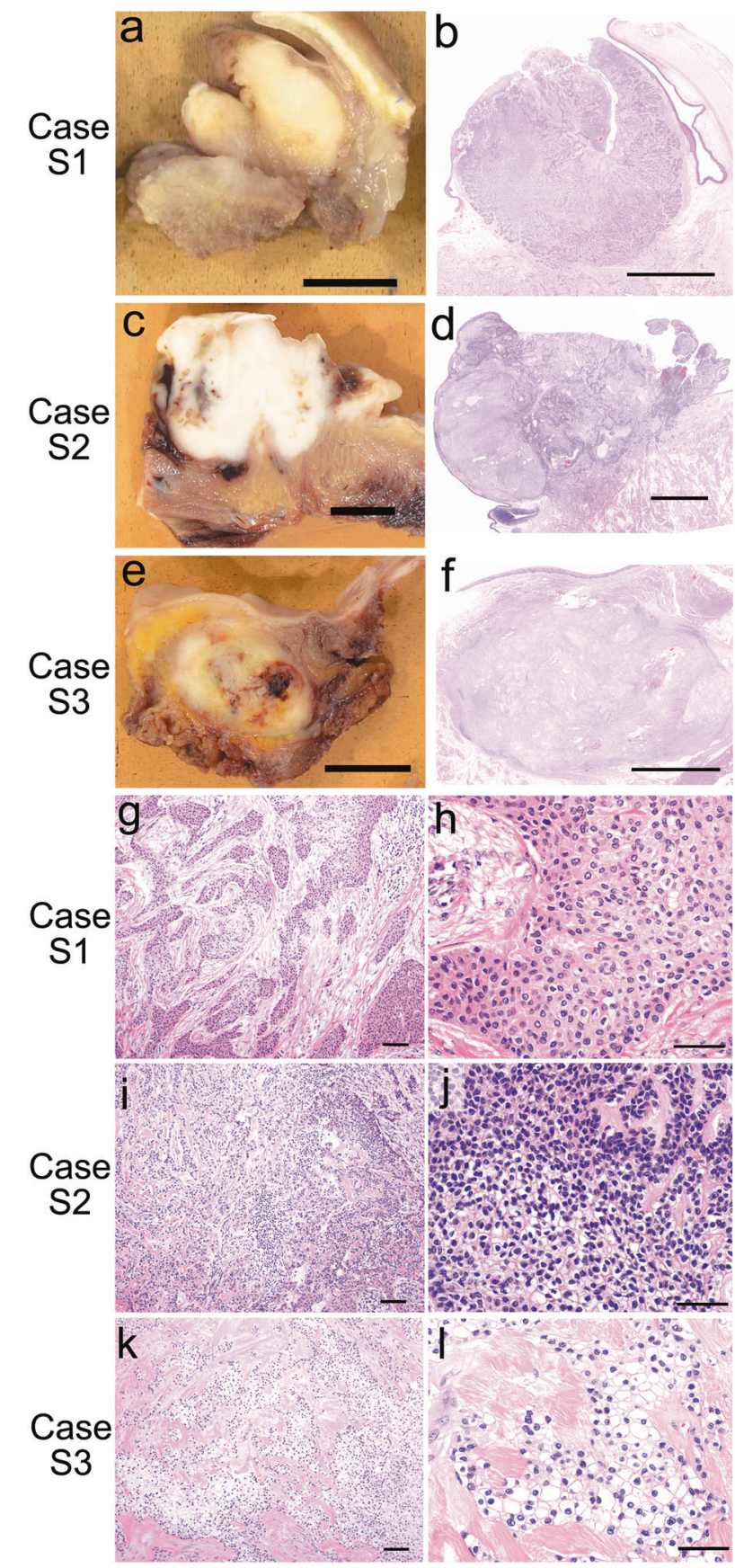

Fig. 3 Gross and histologic findings of salivary hyalinizing clear cell carcinomas. The lesions are well-demarcated, creamy whitish a, e or whitish c color and are located immediately beneath the mucosa, adjacent to salivary glands $\mathbf{b}, \mathbf{d}, \mathbf{f}$. Note trabecular patterns $\mathbf{g}$ and nest formation i, $\mathbf{k}$ with hyalinized collagen. Predominant eosinophilic cells $\mathbf{h}, \mathbf{j}$ and clear cells $\mathbf{l}$ are seen in various proportions. (Hematoxylin and eosin staining. Scale bars are $10 \mathrm{~mm}$ in $\mathbf{a}, \mathbf{c}$, and e, $5 \mathrm{~mm}$ in $\mathbf{b}, \mathbf{d}$, and $\mathbf{f}$, $100 \mu \mathrm{m}$ in $\mathbf{g}, \mathbf{i}$, and $\mathbf{k}$, and $50 \mu \mathrm{m}$ in $\mathbf{h}, \mathbf{j}$, and $\mathbf{l}$.)

Furthermore, one of the $3^{\prime}$-ATF1 (blue signals, Fig. 5a, middle column) was fused to $5^{\prime}$-EWSRl, resulting in a purple to pink signal (Fig. 5a, right column). This fusion assay clearly demonstrated that two specific genes are 


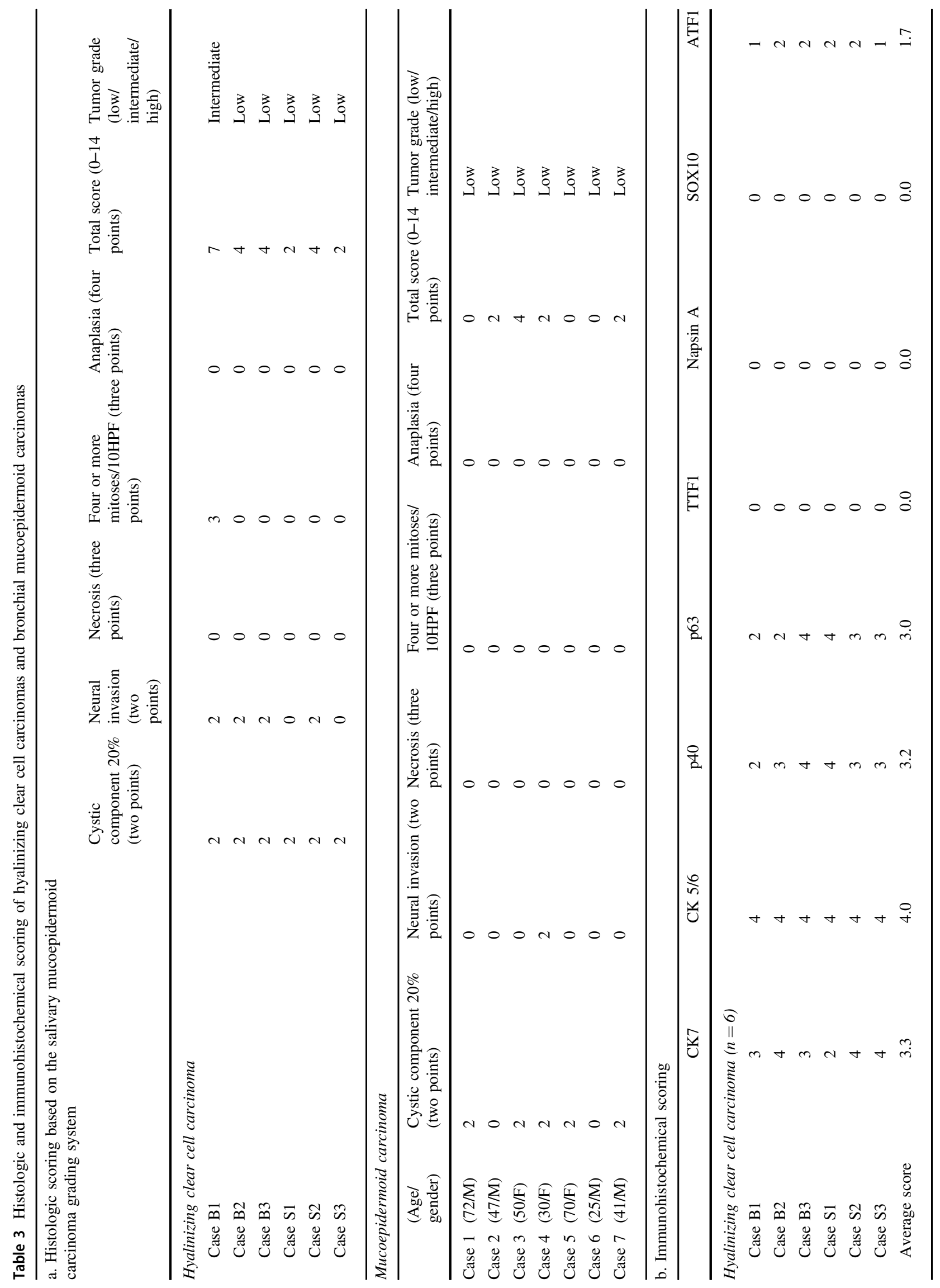




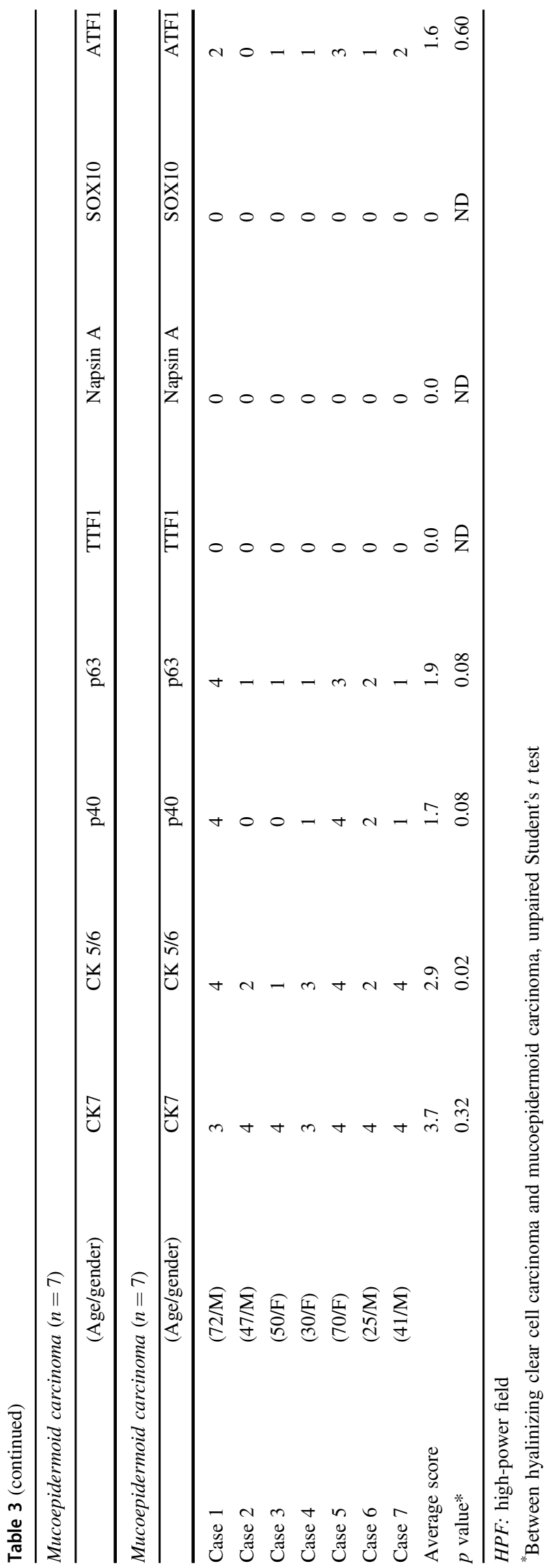

involved in hyalinizing clear cell carcinoma, and provide definite and convincing evidence for differential diagnosis. All three salivary hyalinizing clear cell carcinoma cases were also positive for EWSRI split signals (data not shown).

\section{RT-PCR and Sanger sequencing}

RT-PCR revealed EWSR1-ATF1 fusion transcripts in all the three bronchial hyalinizing clear cell carcinomas, whereas no transcript was identified in normal lung tissue (Fig. 5b). All samples including normal tissue showed $A C T B$ transcripts, providing assurance of quality (Fig. 5b). The results of Sanger sequencing confirmed the presence of EWSRl-ATFl gene, and their fusion points (EWSR1exon 11 and $A T F 1$-exon 3) were completely identical (Fig. 5c). Moreover, these fusion points are identical to those previously reported for bronchial and salivary hyalinizing clear cell carcinomas $[14,20]$. Taken these findings together, the three bronchial tumors were definitely confirmed as hyalinizing clear cell carcinomas.

\section{Discussion}

Hyalinizing clear cell carcinoma of the bronchial glands is very rare, $<0.1 \%$ at our hospital, but there are several distinctive features such as a clear cell components, hyalinizing stroma, and low-grade cytological atypia. However, since their appearance varies from case to case, they have been classified simply as clear cell carcinoma, not otherwise specified [23]. The chimeric gene, EWSRl$A T F 1$, already known to characterize clear cell sarcoma of soft tissue [24], was identified also in salivary gland hyalinizing clear cell carcinoma [20]. More recently, additional two cases of hyalinizing clear cell carcinoma of bronchial gland origin were reported, harboring an identical gene rearrangement $[14,17]$. Here, we successfully identified the chimeric gene in all of our cases, implying that the diagnosis of hyalinizing clear cell carcinoma is definite. Although we believe that the final diagnosis of hyalinizing clear cell carcinoma should be made by confirming gene fusion, conventional diagnostic approaches such as immunohistochemistry can be improved and we will point to this tumor without FISH or RT-PCR analyses.

The most characteristic feature of hyalinizing clear cell carcinoma is the clear cell component with hyalinizing stroma, but our results showed that the proportions of these components varied among the cases. Differential diagnosis of bronchial hyalinizing clear cell carcinoma on histological criteria must rule out mucoepidermoid carcinoma, squamous cell carcinoma, adenocarcinoma, and metastatic clear cell renal cell carcinoma. Hyalinizing clear cell 

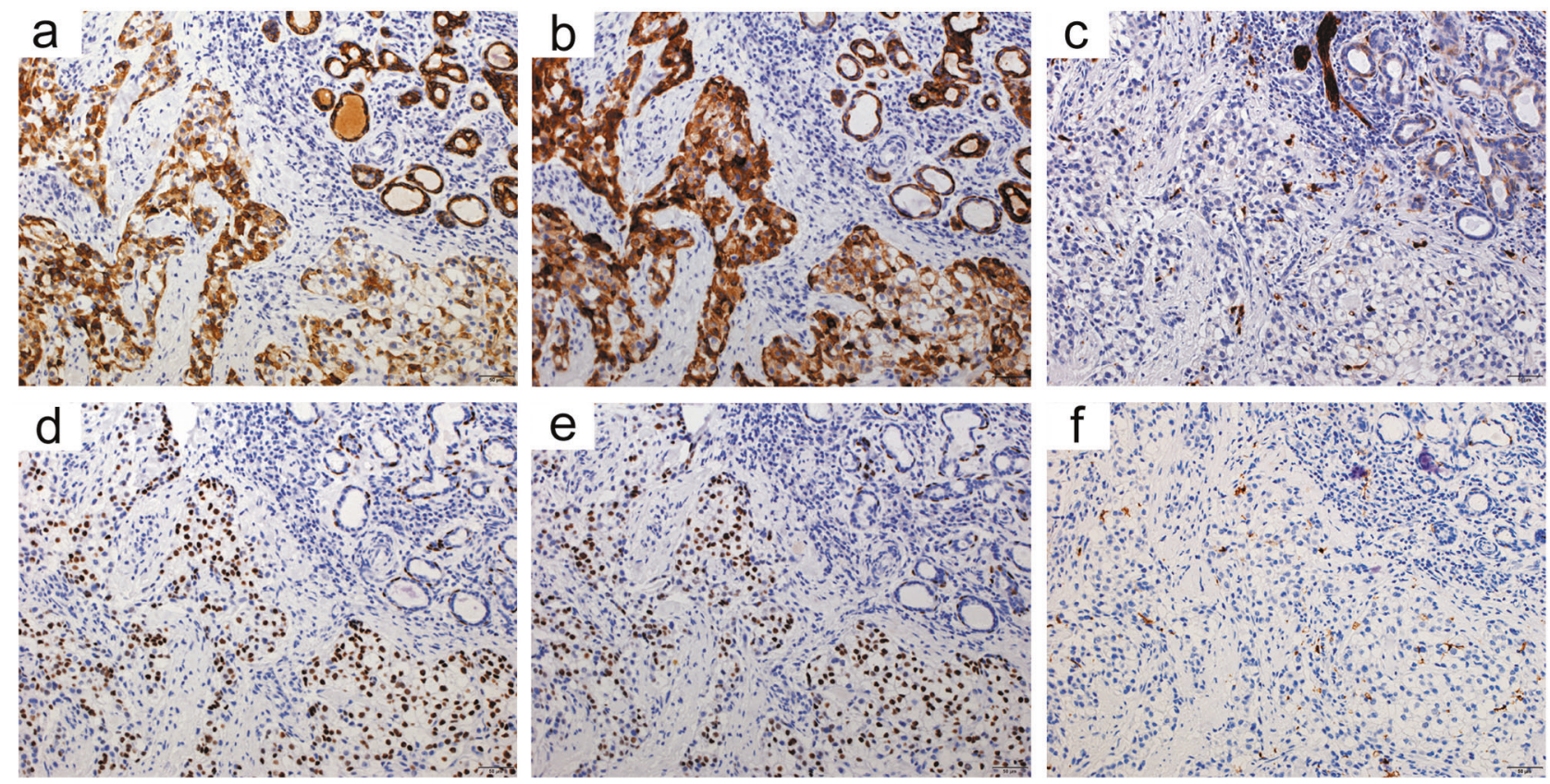
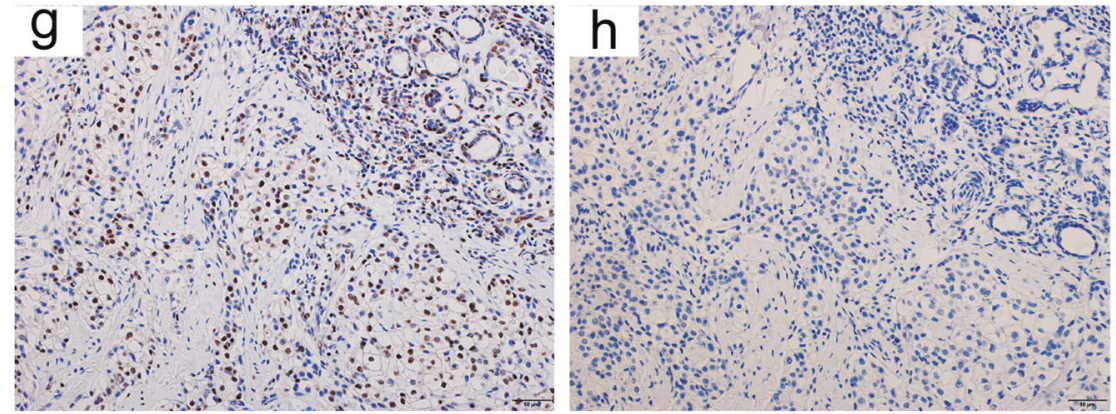

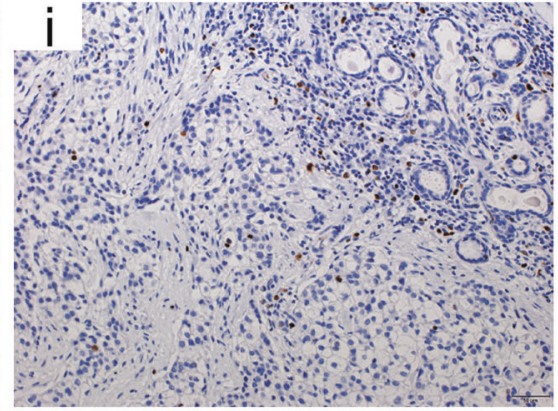

Fig. 4 Representative immunostaining results for a bronchial hyalinizing clear cell carcinomas (case B2). Tumor cells express CK7 a, CK 5/6 b, p40 d, and p63 e, but negative for S100 c. However, intermingled stellate cells are positive for $\mathrm{S} 100 \mathbf{c}$, and also for CD1a $\mathbf{f}$.

carcinoma partially shares histologic features with these, and distinction from mucoepidermoid carcinoma is particularly challenging. Bronchial mucoepidermoid carcinoma also shows a variety of histologic features, including clear cells, intermediate cells, mucin-rich cells, and hyalinizing stroma. In Fig. 2a, clear cells and eosinophilic intermediate cells are seen to be in gradual transition into each other, resembling bronchial hyalinizing clear cell carcinoma. Similarly, hyalinizing collagen bundles and occasional gland formation are shared in common with hyalinizing clear cell carcinoma. Importantly, mucin-rich cells of bronchial mucoepidermoid carcinoma are never seen in the bronchial and salivary hyalinizing clear cell carcinoma. Therefore, the presence of mucin-rich cells indicates a diagnosis of mucoepidermoid carcinoma.

Squamous cell carcinoma of lung is another important differential diagnosis, particularly in the case with prominent clear cell feature. Squamous cell carcinoma typically lacks mucin production and sometimes shows
Tumor cells express ATF1, but non-tumor cells such as lymphocytes are positive as well g. Tumor cells are uniformly negative for HMB45 h. The Ki-67 labeling index is low, at around $5 \% \mathbf{i}$

keratinization, which may be helpful for discriminating hyalinizing clear cell carcinoma from squamous cell carcinoma. However, it will be insufficient to rely only on these features on limited samples such as biopsy specimens. Following features may be further helpful to discriminate hyalinizing clear cell carcinoma from squamous cell carcinoma; nuclei are round and less atypical with inconspicuous nucleoli, and tumor cells form smaller nests or trabeculae without peripheral nuclear palisading. To avoid misinterpretation, it is important to evaluate whole sections for specific characteristics of these tumors.

Immunohistochemical analysis can provide useful findings especially when material is limited as with biopsy specimens. For example, with some lung adenocarcinomas featuring clear cells, TTF-1 and/or Napsin A positivity may be helpful to distinguish these tumors from hyalinizing clear cell carcinomas. Since all hyalinizing clear cell carcinoma cases were positive for $\mathrm{p} 63$ and CK5/6, metastatic clear cell renal cell carcinoma can be ruled out since it is consistently 


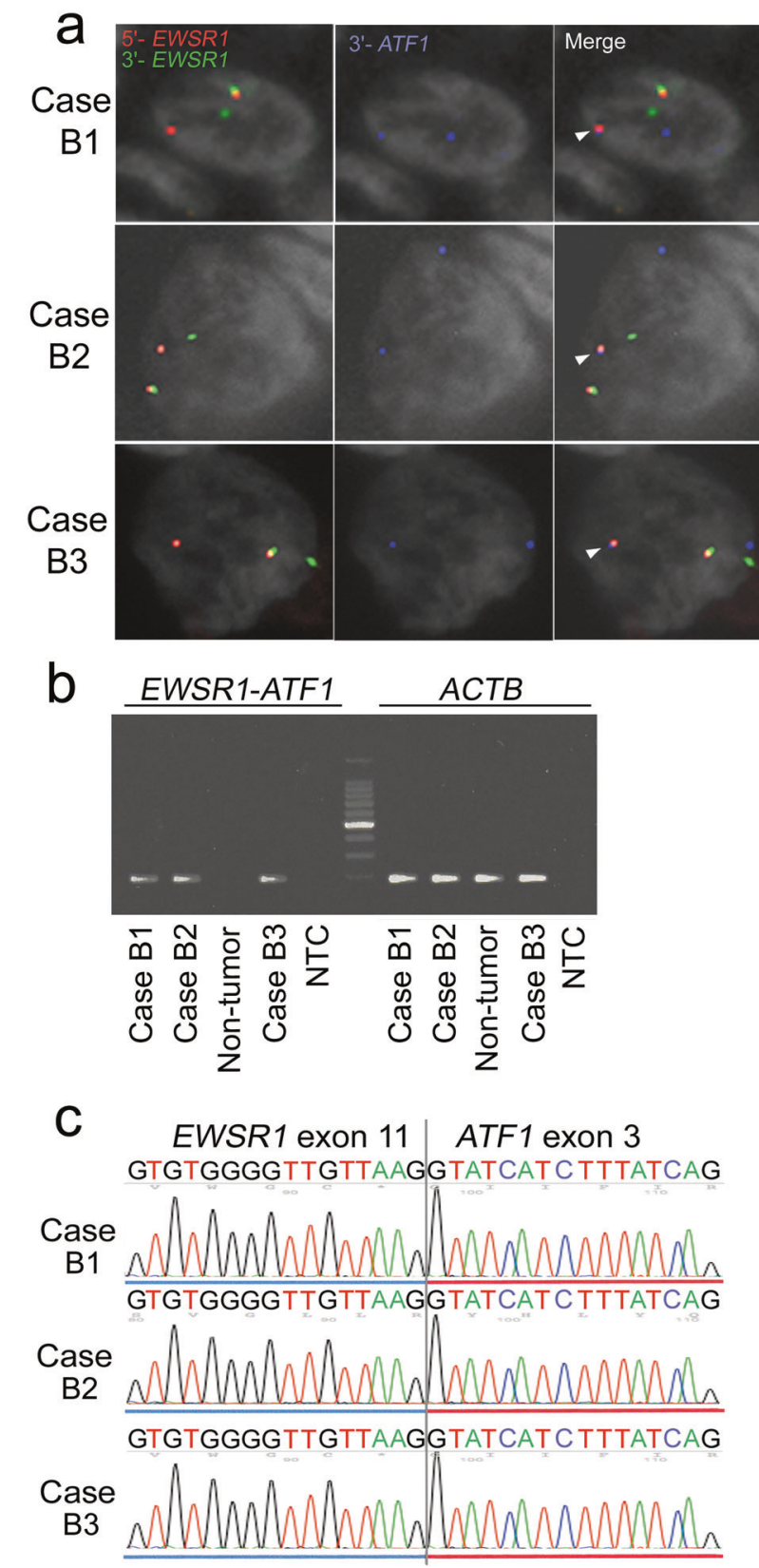

Fig. 5 Detection of the chimeric gene, EWSR1-ATF1. a Fluorescence in situ hybridization shows split signals for EWSR1 (left column, red and green signals). 5'-EWSR1 (red signal) is fused to $3{ }^{\prime}-A T F 1$ (blue signal), resulting in a pink signal (right column, arrow head). b EWSR1-ATF1 fusion transcripts were detected in all bronchial hyalinizing clear cell carcinoma cases, whereas no transcript is identified in normal lung ("non-tumor") tissue (left half). All samples including normal lung tissues show the $A C T B$ transcript, assuring the quality (right half). c Sanger sequencing indicates the presence of EWSR1$A T F 1$ gene with fusion points of EWSRI-exon 11 and ATF1-exon 3

negative for these markers $[25,26]$. On the other hand, CK5/6 staining is not useful to discriminate hyalinizing clear cell carcinoma from squamous cell carcinoma and mucoepidermoid carcinoma, which may also be positive.
Immunohistochemically, since both of the hyalinizing clear cell carcinomas and squamous cell carcinoma are positive for basal cell markers such as p40 and p63, they are not useful to distinguish these tumors.

Because hyalinizing clear cell carcinoma harbors the EWSR1-ATF1 chimeric gene, all the hyalinizing clear cell carcinoma cases were positive for ATF1. However, nontumorous cells and some bronchial mucoepidermoid carcinoma are also positive, so the ATF1 staining is not necessarily useful to distinguish these tumors. Clear cell sarcoma shows positive staining for HMB45, S100, and SOX10, whereas all bronchial hyalinizing clear cell carcinoma cases are negative for these markers. It thus appears important to combine immunohistochemical and FISH results to make a correct diagnosis.

The etiological factors of bronchial hyalinizing clear cell carcinoma are unclear, but considering our own and previously reported cases, we can point to age distribution in the fourth to sixth decades, no gender preponderance or relation to smoking history, and with a predilection for the right lung. In addition, tumor cells showed the low Ki-67 labeling index, indicating slow growth. Indeed, in case B3, the tumor appeared to have grown slowly to reach the size of $33 \mathrm{~mm}$ over 7 years. Nevertheless, we should bear in mind that distant metastasis of hyalinizing clear cell carcinoma can occur. Su et al. [18] reported two cases of salivary gland hyalinizing clear cell carcinoma with metastases to cervical lymph nodes 10 and 14 years after local resection. More recently, Wang et al. [15] reported a case with late recurrence of bronchial hyalinizing clear cell carcinoma. These findings indicate that bronchial hyalinizing clear cell carcinoma has the potential to metastasize late after surgery, even in a form of an occult cancer, so that careful long-term follow-up should be recommended. In addition, since bronchial and salivary hyalinizing clear cell carcinomas show exactly the same characteristics, thorough clinical examination is crucial to rule out a metastatic hyalinizing clear cell carcinoma.

In summary, we here presented three rare bronchial hyalinizing clear cell carcinoma cases, focusing on histologic and FISH findings, and verified the similarity of tumors originating in the lung and the salivary glands. Considering the rarity of the tumor, it is important to remember this entity as one of the differential diagnoses of salivary gland-type lung tumors.

Acknowledgements We thank Tomoyo Kakita, Motoyoshi Iwakoshi, Mikiya Takeuchi, and Haruna Oikawa for expert technical assistance.

\section{Compliance with ethical standards}

Conflict of interest The authors declare that they have no conflict of interest. 


\section{References}

1. Falk N, Weissferdt A, Kalhor N, et al. Primary pulmonary salivary gland-type tumors: a review and update. Adv Anat Pathol. 2016;23:13-23.

2. Meckstroth CV, Davidson HB, Kress GO. Mucoepidermoid tumor of the bronchus. Dis Chest. 1961;40:652-6.

3. Nomori H, Kaseda S, Kobayashi K, et al. Adenoid cystic carcinoma of the trachea and main-stem bronchus. A clinical, histopathologic, and immunohistochemical study. J Thorac Cardiovasc Surg. 1988;96:271-7.

4. Carretta A, Libretti L, Taccagni G, et al. Salivary gland-type mixed tumor (pleomorphic adenoma) of the lung. Interact Cardiovasc Thorac Surg. 2004;3:663-5.

5. Shanks JH, Hasleton PS, Curry A, et al. Bronchial epithelialmyoepithelial carcinoma. Histopathology. 1998;33:90-1.

6. Travis WD, Brambilla E, Burke AP, et al. World Health Organization Classification of Tumors: WHO Classification of Tumours of the Lung, Pleura, Thymus and Heart. Lyon, France: IARC Press; 2015.

7. Azukari K, Yoshioka K, Seto S, et al. Adenoid cystic carcinoma arising in the intrapulmonary bronchus. Intern Med. 1996;35:407-9.

8. Milchgrub S, Gnepp DR, Vuitch F, et al. Hyalinizing clear cell carcinoma of salivary gland. Am J Surg Pathol. 1994;18:74-82.

9. Rinaldo A, McLaren KM, Boccato P, et al. Hyalinizing clear cell carcinoma of the oral cavity and of the parotid gland. ORL J Otorhinolaryngol Relat Spec. 1999;61:48-51.

10. Zhao W, Yang L, Wang L, et al. Primary clear cell carcinoma of nasal cavity: report of six cases and review of literature. Int J Clin Exp Med. 2014;7:5469-76.

11. Ereno C, Grande J, Alija V, et al. Hyalinizing clear cell carcinoma of the hypopharynx metastasizing to the lung: a case report. Histopathology. 2000;37:89-91.

12. Hijjawi SB, Abdullah SE, Abdelhadi K, et al. Hyalinizing clear cell carcinoma of the tonsil and its treatment. Oral Surg Oral Med Oral Pathol Oral Radiol. 2012;114:e32-6.

13. Shah AA, Mehrad M, Kelting SM, et al. An uncommon primary lung tumour: hyalinizing clear cell carcinoma, salivary gland-type. Histopathology. 2015;67:274-6.
14. Garcia JJ, Jin L, Jackson SB, et al. Primary pulmonary hyalinizing clear cell carcinoma of bronchial submucosal gland origin. Hum Pathol. 2015;46:471-5.

15. Wang H, Li WY, Kuo YJ, et al. Primary pulmonary hyalinising clear cell carcinoma with mucin production and delayed metastases after 16 years. Pathology. 2016;48:518-21.

16. Shahi M, Dolan M, Murugan P. Hyalinizing clear cell carcinoma of the bronchus. Head Neck Pathol. 2017;11:575-9.

17. Jeffus SK, Gardner JM, Steliga MA, et al. Hyalinizing clear cell carcinoma of the lung: case report and review of the literature. Am J Clin Pathol. 2017;148:73-80.

18. Su HK, Wang BY, Mannan AA, et al. Very delayed cervical lymph node metastases from hyalinizing clear cell carcinoma: report of 2 cases. Head Neck. 2015;37:E19-21.

19. Newman WC, Williams L, Duvvuri U, et al. Hyalinizing clear cell carcinoma with biopsy-proven spinal metastasis: case report and review of literature. World Neurosurg. 2016;90:699.e7-10.

20. Antonescu CR, Katabi N, Zhang L, et al. EWSR1-ATF1 fusion is a novel and consistent finding in hyalinizing clear-cell carcinoma of salivary gland. Genes Chromosomes Cancer. 2011;50:559-70.

21. Auclair PL, Goode RK, Ellis GL. Mucoepidermoid carcinoma of intraoral salivary glands. Evaluation and application of grading criteria in 143 cases. Cancer. 1992;69:2021-30.

22. Roden AC, Garcia JJ, Wehrs RN, et al. Histopathologic, immunophenotypic and cytogenetic features of pulmonary mucoepidermoid carcinoma. Mod Pathol. 2014;27:1479-88.

23. Yang S, Zhang J, Chen X, et al. Clear cell carcinoma, not otherwise specified, of salivary glands: a clinicopathologic study of 4 cases and review of the literature. Oral Surg Oral Med Oral Pathol Oral Radiol Endod. 2008;106:712-20.

24. Zucman J, Delattre O, Desmaze C, et al. EWS and ATF-1 gene fusion induced by $\mathrm{t}(12 ; 22)$ translocation in malignant melanoma of soft parts. Nat Genet. 1993;4:341-5.

25. Langner C, Ratschek M, Tsybrovskyy O, et al. P63 immunoreactivity distinguishes upper urinary tract transitional-cell carcinoma and renal-cell carcinoma even in poorly differentiated tumors. J Histochem Cytochem. 2003;51:1097-9.

26. Nolan LP, Heatley MK. The value of immunocytochemistry in distinguishing between clear cell carcinoma of the kidney and ovary. Int J Gynecol Pathol. 2001;20:155-9. 